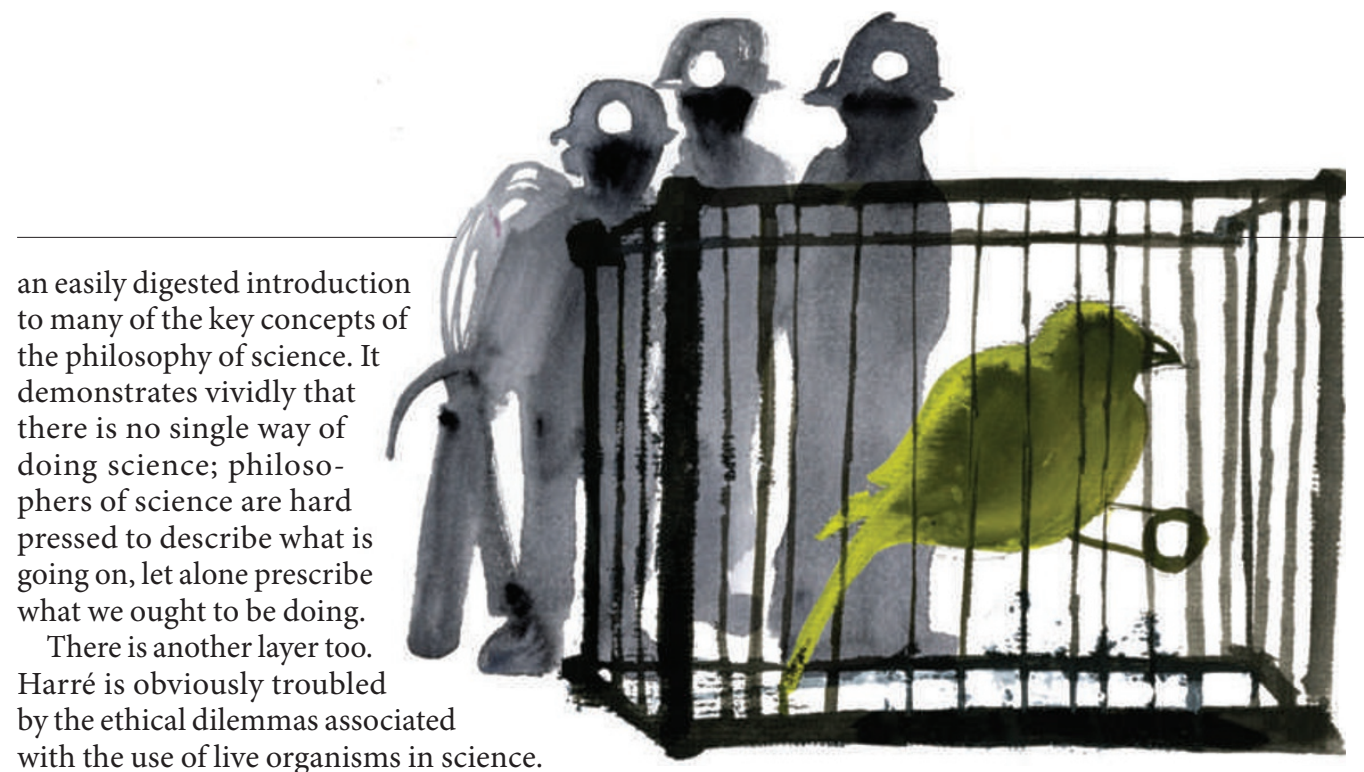

with the use of live organisms in science.

He argues, quite rightly, that it makes no sense to hold strong views on animal experimentation without having a sound understanding of how science works, of how and why animals have been used, and the unpredictable gains that can result. The book does a terrific job of generating that understanding. Even the inclusion of examples that, at first glance, have little to do with animal experimentation - plants, worms on mounds of methane ice, and virtual animals such as the titular cat and Richard Dawkins' biomorphs - bring into sharp focus issues that are central to the political debate. Harré discusses the merits of inanimate and non-sentient alternatives, and the unpredictable value of generalizing from model organisms.

This book should be compulsory reading for activists who man the barricades, throw the bombs or step up to the microphone. As Harré says, "Only when we have a clear idea of what has been done by whom and for what purpose can we take up the pressing moral questions that must arise."

But then comes frustration. Having provided that "clear idea", Harré doesn't take up the pressing moral questions. He concludes that there are three dimensions to argue about: the extent to which gaining scientific knowledge is an absolute good, the extent to which other living things have inalienable rights, and the extent to which we ascribe mental lives to other things. But then he dodges the bullet, saying "I leave the working out of moral arguments to others more qualified than I am to reach just and ethically sound conclusions". How much more qualified than Harré can you get?

It is easy to feel that Harré has interesting views that he has not shared. He mentions early on that he has "serious reservations about many projects in which animals have been involved". He hints in two places that experimenting with plants has implications for the animal-experimentation debate. He even says there may be moral issues about working with advance which areas of scientific knowledge are worth knowing. Nor, for the interesting cases, can we tell whether our instrumentation - animate or inanimate - is up to the game. I think the debate on animal experiments is with us for eternity.

Andrew F. Read is professor of biology and entomology at the Pennsylvania State University, University Park, Pennsylvania 16827, USA. e-mail:a.read@psu.edu

\title{
A billionaire's vision for India
}

\section{Imagining India: The Idea of a Renewed \\ Nation \\ by Nandan Nilekani \\ Penguin: 2009.528 pp. $\$ 29.95$}

Nandan Nilekani's book is a product of the new India. The author, a first-generation, wealthy software entrepreneur, belongs to the iconic trinity of that nation - along with the film star and the cricketer, his words command attention.

On graduating in electrical engineering from the Indian Institute of Technology in Bombay in 1978, Nilekani, unlike many of his classmates, did not emigrate to the United States. In 1981, he and six others pooled US $\$ 250$ to start Infosys Technologies, an information-technology (IT) consulting

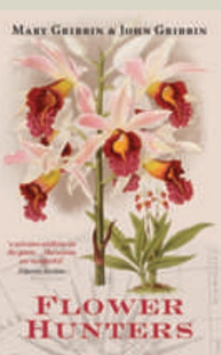

\section{Flower Hunters}

by Mary Gribbin and John Gribbin

(Oxford Univ. Press, \$19.95)

This engaging collection tells the stories of 11 remarkable 'flower hunters' who travelled the globe to discover new plants. It describes the impacts they had on both gardening and science, highlighting the difficulties they experienced on their travels and when trying to propagate the plants they brought back with them.

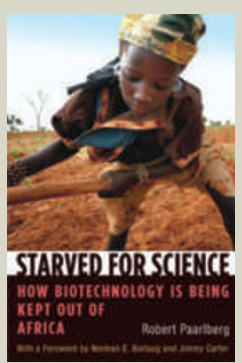

Starved for Science: How Biotechnology Is Being Kept Out of Africa

by Robert Paarlberg

(Harvard Univ. Press, \$16.95)

In this controversial book, Robert Paarlberg argues that opposition to agricultural science in prosperous countries is reaching Africa, denying poor farmers access to technologies that might improve their yields - especially transgenic crops with insect- or drought-resistance. 
education almost for free, would produce the leaders of tomorrow. As Nilekani points out, "India set off on a path of knowledge-intensive growth that was both unique and unusual for a developing economy".

The policies of planned development and state-financed education gave less-privileged children access, first to intellectual capital and later to bank loans. Thus, a strong foundation was laid before some of Nehru's economic policies were reversed in the 1990s.

The author's training in engineering is reflected in the modular structure of Imagining India. Nilekani interviews more people than a journalist would and cites as many sources as an academic. The former may see him as a rival in recycling the views of others, and the latter may find him lacking in rigour. But as an IT expert, the author knows a thing or two about 'crowd sourcing' - of information and knowledge.

This book is not the story of Infosys. Nilekani has chosen a broader canvas. He takes in the whole range of the nation's maladies - a frozen mindset, inequity, the halting economic reforms, bumbling bureaucrats, caste-biased sectarian politicians, unethical businessmen, inadequate infrastructure and a crippled

higher-education system. His strongest comments are reserved for the failures in the education sector, which lacks competition and quality control and is marked by a proliferation of degree-giving institutions, a shortfall of teachers and a lacklustre administration.

Nilekani laments the sharp polarization of discourse in all of India's spheres - political, economic and social. The mindless 'for or against' clashes that occur trivialize important issues and leave little scope for reasoned debate and policy-making. Such conflicts raise barriers against change and stunt the growth of new ideas. In my view, such polarization and the weakening social cohesion constitute a far greater danger than a temporary dip in the economic growth rate. However, no fault line shakes the author's optimism.

Nilekani is critical of the early quasi-socialist policies of planned development, staterun enterprises and industrial licensing that stifled initiative and kept entrepreneurs and the economic growth rate shackled. But he is

state-run space, atomic energy and other research programmes also nurtured hundreds of ancillary enterprises.

Nilekani pleads for innovation in business and governance. He refers to projects that enable slum children and illiterate farmers to gain access to computers and the Internet, and discusses grass-roots innovations based on the Indian tendency to improvise. He describes the jugaad, a multipurpose 'car' made by rural mechanics who put together whatever parts they can lay their hands on. Regrettably, he does not devote much space to India's strengths in advanced technology development.

Nilekani sees a great future for India, provided it speeds up economic reforms towards more market-led growth in the global arena, and adopts new ways of thinking to counter statism and bureaucracy. He is heartened by the change in people's attitude in favour of entrepreneurship, globalization and the English language. He hails India's billion-strong population, with a median age of 23, as its demographic dividend.

Nilekani notes that "all our major strengths have come together and matured at the same time". By

not handcuffed to dogma. Nor does he spare private enterprise from criticism. He agrees that it was the legacy of those socialist policies that brought the country certain advantages when it decided to take the path of economic liberalization in the 1990s. His own business has drawn on the pool of talent directly nurtured by the state.

Part of the Nehruvian legacy is the country's competence in science and technology, most of it built up in the public sector. This competence came in handy when the private sector became mature enough to use it in industries such as biotechnology, IT and electronics. The using the rare opportunity provided by a constellation of domestic and international factors, he believes that India can reach farther and higher. Yet, he warns, such windows of opportunity do not remain open for long.

Hope has been an enduring characteristic of the Indian civilization. At a time when possibility has just encountered feasibility, Imagining India carries a strong message of hope.

L. K. Sharma is former foreign correspondent of The Times of India and editor of the book Innovative India Rises.

e-mail:sharmalk@gmail.com

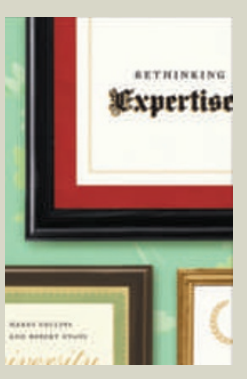

\section{Rethinking Expertise}

by Harry Collins and Robert Evans

(Univ. Chicago Press, E15.50)

By classifying different types of expertise, Harry Collins and Robert Evans make the case for a radical rethink of what constitutes expertise and how to exploit it. "Collins and Evans put their points vividly, with elegant language and diagrams," wrote Robert P. Crease (Nature 450, 350-351; 2007).

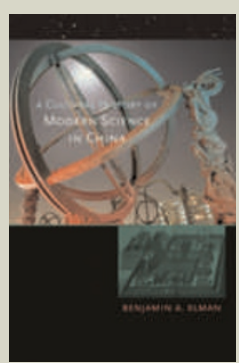

A Cultural History of Modern Science in China by Benjamin A. Elman

(Harvard Univ. Press, \$17.95)

In this concise, accessible, but comprehensive book, Benjamin Elman describes the effects on science of the Jesuit mission in imperial China in 1600-1800, and the later influence of Protestants in the nineteenth century. By doing so, he places the emergence of modern science in China in historical context. 